\title{
Workplace Spirituality as an Antecedent of University Teachers' Subjective Well-being: Mediating Role of Job Satisfaction and Job Performance
}

\author{
S. Pavan Kumar \\ School of Management, National Institute of Technology Karnataka, Surathkal \\ pavankumar@nitk.ac.in
}

\begin{abstract}
There is a need to measure how university teachers' think and feel about their lives, especially when the work environment is dynamic and ever-changing. In this study, the scholar explores workplace spirituality's association with the teachers' subjective well-being directly and also indirectly through teachers' job satisfaction and job performance. Data were collected through survey instrument from 395 teachers' working for various private engineering institutions located in the states of Telangana and Andhra Pradesh. Results showed a relationship between workplace spirituality and subjective well-being directly, although the path coefficient was weak.
\end{abstract}

Interestingly, the results discovered the positive and significant indirect relationship between workplace spirituality and subjective well-being through teachers' job satisfaction and job performance. The papers aim was to explore conceptually the role of spirituality contributing to University teachers' satisfaction with life as a whole, which is essentially the teachers' subjective well-being. The present study is probably one of its kind to explore the relationship between workplace spirituality and subjective well-being not only directly but also indirectly through job satisfaction and job performance. The outcomes of the study offer valuable insights and inputs for future research in the niche area of workplace spirituality. The implications of the study have been discussed in greater detail in the appropriate section.

Keywords: Spirituality, subjective well-being, Job involvement, and Job satisfaction

\section{Introduction}

There has been a phenomenal growth of private colleges as well as universities in India with the status of either deemed to be universities or private universities in recent years, believing that people armed with new knowledge in the field of technology would contribute better to the growth and development of the country. However, according to Umashankar and Dutta (2007), higher education is expanding, but mostly in an unplanned manner, without even minimum levels of checks and balances. Some of the institutions maintain their standards, whereas most of the institutions are struggling to achieve the required standard, leading to the closure of many such institutions either by the regulatory agencies or sometimes voluntary by the management of such institutions. Thus, it becomes essential to critically examine the present trends in engineering education to ensure its effectiveness to face the challenges of the 21 st century.

It is known that the teacher is the most important source for any educational institution as they are the one who can bring laurels to the institution. Pfeffer (1998) observed that human resource should be put first in making profits and refers to those practices as people centric strategies. For educational institutions, teachers' capabilities are an important source of competitive advantage, as they cannot be easily imitated (Kumar \& Giri, 2015). The 'process' and 'information technology' aspects of an organization are changing continuously, and they are getting replicated by competitors. It is estimated that competitors secure detailed information on 70 per cent of new products within one year of introduction and that 60 to 70 per cent of all 'process learning' is eventually acquired by competitors (Slater, 1995). Hence, to the maximum extent, the effectiveness of engineering institutions depends on teachers' performance in particular than on physical assets.

In recent literature, it is reported that job satisfaction and job performance are among important issues when studying human attitudes and behaviours (Abdullah, Bilau, Enegbuma, Ajagbe, \& Ali, 2011). The concept of job satisfaction has led to a growing interest in knowing how one's feeling of satisfaction or dissatisfaction changes and its consequences on employee performance. Job satisfaction is also expected to predict pleasant emotional feelings such as well-being, joy, enthusiasm, happiness, and fulfilment, among many others. Therefore, the dynamic aspects of job satisfaction are one of the focal points of this study.

The acceptance of the concept of spirituality is increasing greatly in the field of human resource management and behavioural research. People at the helm of responsibility are looking at spirituality to solve modern-day challenges at the workplace. Workplace spirituality has been found to have a positive impact on job satisfaction (Bodia \& Ali, 2012). Other lines of researchers have started to explore the probable association between workplace spirituality and performance/productivity of employees. Pandey, Gupta and Arora (2009) also highlighted an aspiring association 
between workplace spirituality and employees' performance. Workplace spirituality has been recognized as a means to enhance employees' well-being at the workplace. Krishnakumar and Neck (2002) have emphasized on the reinforcement of spirituality for employee well-being in the best interest of organizations on the whole. There is an increasing confirmation from the literature review that workplace spirituality programs have a significant positive impact on the individual level outcomes for employees, such as job satisfaction (Fry, 2005), personal well-being and job performance (Milliman et al., 1999).

For educational institutions, teachers' well-being is the important parameter, since teachers' who are high in subjective wellbeing are more productive, more creative and tend to have better social relations (De Neve, Diener, Tay, \& Xuereb., 2013). University teachers' who are high in subjective well-being are more likely to experience positive feelings, motivates people to succeed at work and they persist with efforts to attain their goals. Peterson, Luthans, Avolio, Walumbwa, and Zhang., (2011) found that happy workers are optimistic, hopeful, resilient and high in selfefficacy. Individuals who report high subjective well-being give more to their communities in terms of both time and money. According to Harter, Schmidt and Hayes (2002), employees spent a substantial portion of their life at the workplace and thus employer should encourage employee well-being at the workplace.

After having understood the enormous benefits a teacher with high subjective well-being can offer, it is imperative to identify the antecedents of subjective well-being among the university teachers. There exist many studies in the field of spirituality. However, they are mostly qualitative in nature until the advent of survey instruments very recently. Giacalone and Jurkiewicz (2003) collected a number of articles dedicated to workplace spirituality; unfortunately, articles based on empirical research design were very few. Although a few studies hint towards the association of workplace spirituality and employee well-being, there is a scarcity of empirical evidence to confirm the association (Garg, 2017). Hence, the present study is designed to supplement this niche in the literature by understanding the association between employee spirituality and employee subjective well-being directly and also through the intervening variables such as employee job satisfaction and job performance.

\section{Literature Review}

\section{A. Teachers' Workplace Spirituality}

Spirituality offers an outline for leading both personal and professional life successfully. Mitroff and Denton (1999) described 'spirituality' as an indispensable feeling that is associated with one's self, society and the universe as a whole. They were of the opinion that spirituality is a kind of individual trait and is deeply personal in nature. Research on "workplace spirituality" has begun to gain more attention in recent past, this might be because people spend much of their time in their workplace and hence positions as an important place for experiencing meaning, purpose and creating social identities. According to Fry (2003), "workplace spirituality is a contemporary topic in organizational literature which is having a limited theoretical development". Saas (2000) has unequivocally stated that "the emerging body of academic literature on spirituality in organizations exhibits more breadth than the depth". Pawar, S. B (2009) has identified that empirical research on the effects of workplace spirituality on organizational outcomes is inadequately examined. Hence, workplace spirituality qualifies for more examination in terms of its consequential effects in the workplace.

\section{B. Teachers' Job Satisfaction}

The majority of the studies conducted on job satisfaction are primarily built upon job motivation theory. Job satisfaction expresses the relationship between human experiences and emotions with work and work environment. Job Satisfaction is an attitudinal variable relate to how an employee perceives his/her work experience in the current job and organization. Job satisfaction refers to a collection of attitudes that workers have about their jobs (Johns \& Saks, 2001). Job satisfaction involves an individual's attitudes toward work, such as achievement, responsibility, and growth (Herzberg, Maunser, \& Snyderman, 1959). Smith, Kendall, and Hulin., (1969) defined job satisfaction as "the feelings a worker has about his job," noting, "there are different feelings corresponding to differentiable aspects of the job" (p. 12).

\section{Teachers' Job Performance}

The interest and concern of industrial psychologists, managers, and administrators have escalated significantly in the area of job performance of employees in recent years. Despite the rapid progress in the field of organizational behaviour, knowledge about human problems and poor performance in work continues to be the major challenge faced by the managers today and hopefully in the coming decades as well. The term 'employee job performance' signifies individual's work achievement after exerting required effort on the job which is associated through getting a meaningful work assignment for better functioning (Karakas, 2010). Organizational effectiveness mainly depends on employee job performance (Peng, 2014). Systematic research is required to identify the poor performance of employees. Hence a modest attempt has been made to include teachers' job performance as a valuable construct.

\section{Teachers' Subjective Well-being}

The subjective well-being (SWB) focuses on the aspect of well-being, which is the pursuit of happiness and pleasant life. Subjective well-being (SWB) is one's belief and feelings, describing whether they are spending a pleasant, desirable and rewarding life (Diener, 2012). Veenhoven (1984) defines subjective well-being as the degree to which an individual judges the overall quality of his or her life as a whole in a favourable way. The subjective well-being should reflect the experience of a high level of positive affect, a low 
Journal of Engineering Education Transformations, Volume 33, January 2020, Special issue, eISSN 2394-1707 level of negative affect and a high degree of satisfaction with one's life (Deci \& Ryan 2008). Subjective well-being is an extensively used measure of a person's assessment of every aspect of their life (Zhai, Willis, O'Shea, Zhai, \& Yang., 2013). Research in subjective well-being arena has sought out to explore its predictive variables.

\section{Theoretical Background and Hypotheses Development} performance (Krahnke, Giacalone \& Jurkiewicz, 2003). Above findings motivates us to formulate the following hypothesis:

\section{$\mathrm{H}_{2}$ : Workplace spirituality will be positively associated with teachers' job performance}

\section{Workplace Spirituality and Subjective Well-being}

In the initial days of exploring workplace spirituality, the scholars have identified that the organizations that were more spiritual were more likely to experience many positive outcomes. However, the claims were not being validated by quality research studies (Giacalone \& Jurkiewicz 2003). But later, scholars like Karakas (2010) has done an extensive review of literature on workplace spirituality and had attributed workplace spirituality to positive outcomes of increased morale and commitment, increased employee well-being, and increased employee productivity. Only with the advent of valid and reliable measures of workplace spirituality, quantitative research increased, and more studies focused on individual and organizational outcomes.

\section{A. Workplace Spirituality and Job Satisfaction}

Job satisfaction "is an effective (that is, emotional) reaction to a job that results from the incumbent's comparison of actual outcomes with those that are desired..." (Cranny, Smith, \& Stone., 1992, p.1). As workplace spirituality dimensions fulfil employees' higher-order and spiritual needs (Fry, Vitucci, \& Cedillo., 2005), they should induce a more favourable employee affective response. Harung et al. (1996) found that workplace spirituality as an enhancer of job satisfaction. Thus, there should be a positive relationship between workplace spirituality dimensions and job satisfaction. The meaningful work dimension of workplace spirituality implies work that provides employees with a sense of joy and connects employees to the larger good (Duchon \& Plowman, 2005). Thus, there should be a positive relationship between meaning in work and job satisfaction. Hence the following hypothesis is postulated:

\section{$\mathrm{H}_{1}$ : Workplace spirituality will be positively associated with teachers' job satisfaction}

\section{B. Workplace Spirituality and Employee Job Performance}

We are living in a world of competition and survival. Every individual working for an organization has a role to play, basically to upkeep the expectations of the stakeholders. Rastogi and Pati (2014) asserted that everyone in society has some assigned duty whose performance is mandatory to maintain world order. It is suggested that employee must integrate spirituality in organizational vision, mission, policies and practices so that the potential of workplace spirituality could be felt in every aspect of work-life (Garg, 2017). Spirituality help employees to realize the true meaning of their existence. Saks (2006) suggested that the organizations should develop a holistic spiritual organizational climate that helps employees to realize their true potential. Workplace spiritual values reduce stress, conflict and absenteeism and also enhance work

Workplace spirituality is one of the most sought after area of research among scholars and practitioners. According to Harter, Schmidt and Hayes (2002), an employer should encourage employee well-being at the workplace. The introduction of employee well-being at work endorses a healthy and happy workforce for an organization (Cooper \& Robertson, 2001). Workplace spirituality has been a pivotal tool to increase employees' well-being at the workplace. Krishnakumar and Neck (2002) have reinforced the importance of spirituality for employee well-being; it is in the best interest of not just organizations but also to society at large. Milliman et al., 1999, stated that workplace spirituality is helpful for employee well-being. Although a few studies identified an association of workplace spirituality and employee well-being, there is a scarcity of empirical evidence to confirm the association (Garg, 2017). Spirituality has mostly been neglected in subjective wellbeing research (Miller \& Thorensen, 2003). Based on the above findings and recommendations, the below mention hypothesis has been designed:

\section{$\mathrm{H}_{3}$ : Workplace spirituality will be positively associated with teachers' Subjective well-being.}

\section{Job Satisfaction and Subjective Well-being}

Subjective well-being (SWB) is considered an important component of one's life and is associated with a wide variety of positive outcomes (Bates \& Luciano 2008). Subjective well-being is described as a positive state of mind that involves the whole life experience (Page \& Vella-Brodrick, 2009). Whereas, job satisfaction is defined as a positive emotional state resulting from the assessment of one's job experience (Locke 1976). Evidence from the literature indicates that job satisfaction is strongly and significantly related to subjective well-being. Further, a significant positive relationship between job satisfaction and life satisfaction was found (Judge, Klinger, Simon, \& Yang, 2008). Given that job is a significant part of one's life, the positive correlation between job and life satisfaction is meaningful. In fact, research suggests that the relationship between job and life satisfaction is reciprocal, job satisfaction does affect life satisfaction, but life satisfaction also affects job satisfaction (Judge \& Watanabe, 1993). The relationship between Subjective well-being and job satisfaction is well known, and its causal direction is reciprocal, resulting in a so-called 'spillover' model, where job experiences spill over into other realms of life (Judge \& Watanabe 1993). The above argument makes it possible to construct the following hypothesis:

\section{$\mathrm{H}_{4}$ : Teachers' job satisfaction will be positively associated with teachers' subjective well-being.}




\section{E. Job Performance and Subjective Well-being}

Veenhoven (1984) defines subjective well-being as the degree to which an individual judges the overall quality of her or his life as a whole in a favourable way. The subjective well-being should reflect the experience of a high level of positive affect, a low level of negative affect and a high degree of satisfaction with one's life (Deci \& Ryan 2008). Research in subjective well-being arena has grown rapidly since the 60 s to discover its predictive variables and to develop strategies to promote it (Eid \& Larsen 2008). Cote (1999) suggested that good performance leads to the positive affect of subjective well-being. George and Brief (1992) have noted that people with higher job performance tend to become more engaged and involved in their work, earn more money, have better relations with supervisors and coworkers experiencing higher subjective well-being. Based on the above findings, it is hypothesised that:

\section{$\mathrm{H}_{5}$ : Teachers' job performance will be positively related to teachers' subjective well-being}

F. Spirituality and Subjective well-being: Mediating Role of Job Satisfaction and Job performance

Based on the above theoretical background, it can be argued that teachers' job satisfaction and job performance will mediate the association between workplace spirituality and subjective well-being. In other words, workplace spirituality should indirectly augment subjective well-being. It is said that when an organization is able to follow the spiritual values such as providing purpose to one's work, create a system of work culture that gives importance to openness, and emphasizing the importance of empowering its employees will be able to label themselves as 'spiritual organizations' (Simpson, 2009). It can be drawn on the broaden-and-build theory of positive emotions (Fredrickson \& Losada, 2005) which predicts an upward spiral when individuals experience positive work experiences (emotions) such as spirituality that can broaden cognitive abilities, which in turn leads to a substantial increment in subjective well-being. In an educational institution, positive work culture such as openness, positive work experiences such as identifying every individual work as important can enhance teachers' job satisfaction and performance. In turn, a teacher having satisfied with his/her job situations would derive positive affect. On similar lines, a teacher who is happy with his/her performance would expect the better overall quality of life, peace of mind, and happy, that is well-being. Arguments above suggest that:

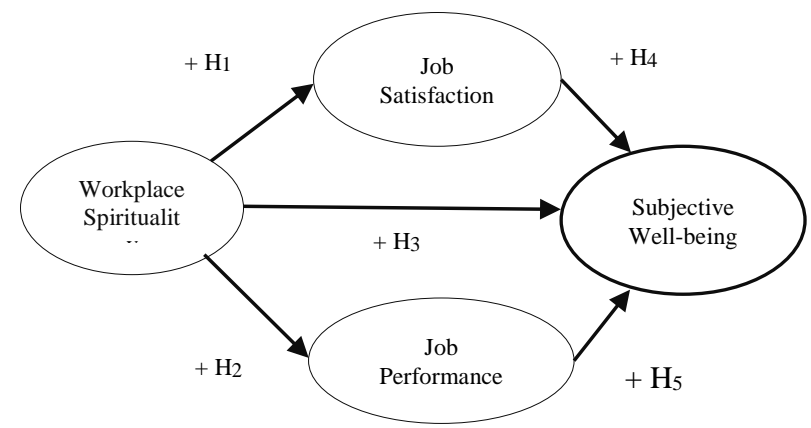

$\mathrm{H}_{6}$ : Teachers' job satisfaction will mediate workplace spirituality and subjective well-being relationship

$\mathrm{H}_{7}$ : Teachers' job Performance will mediate workplace spirituality and subjective well-being relationship

Figure 1: Conceptual Model

\section{Research Framework}

The primary objective of the present research is to explore a direct relationship between workplace spirituality and employee well-being and also indirectly through teachers' job satisfaction and job performance. The research setting for this empirical analysis is private engineering institutions located in two states of Telangana and Andhra Pradesh. The framework is considered as an appropriate one for exploring workplace spirituality, job satisfaction, and job performance as antecedents of subjective well-being. The states of Telangana and Andhra Pradesh has witnessed mushroom of private engineering instructions in last one decade. As pointed by Umashankar and Dutta (2007), higher education is expanding, but mostly in an unplanned manner, without even minimum levels of checks and balances. If these engineering institutions have to success, it is mandatory for them to stand tall among the many competitive private engineering institutions in India and abroad. That can only happen when the teachers' working for those private engineering institutions are experiencing a pleasant, desirable and rewarding life. Hence it becomes imperative to understand and identify a few important antecedents of employee subjective well-being. Random sampling has been used to collect data from teachers' working for various private engineering institutions. Teachers' who were having at least one year of experience with the current engineering institution were considered. It is on the notion that the teachers should have been exposed to their respective work environment before they start providing responses to the survey instrument. Further, while administering the questionnaire, care has been taken to collect the data from all categories, such as men, women, highly experienced to less experienced ones, aged personnel to fresh recruits, etc. The present study is based on a sample of 395 teachers. Female respondents comprise only 37.5 per cent of the sample, which means 148 of the total respondents were female and male employee contributed 62.5 per cent, that is, 247 of the total respondents. The average age of the respondents was 35.5 years.

\section{Data Collection}

Primary data were collected through a structured questionnaire. Part A of the questionnaire captured the respondents' demographic information, such as age, gender, work experience, educational qualification and designation etc. Part B measured teachers' workplace spirituality (independent variable), teachers' job satisfaction and job performance (Mediating variables) and teachers' subjective well-being (outcome variable).

\section{Conceptualization and Operationalization of Variables}


Journal of Engineering Education Transformations, Volume 33, January 2020, Special issue, eISSN 2394-1707 There is an array of survey instruments available to the researchers to measure the study variables. It would always be desirable to check the suitability such survey instruments keeping the context and psychometric properties in mind. The present study uses the following scales:

Workplace spirituality is conceptualized around spiritual values such as providing purpose to one's work, create a system of work culture that gives importance to openness, and induce spirit to energize the work. An extensive review on workplace spirituality by Houghton et al. (2016) concluded that the three-dimensional framework such as inner life, meaningful work, and sense of community defined by Ashmos and Duchon (2000) is most widely accepted by the research community. The current study uses single dimension 'meaningful work' of workplace spirituality scale developed by (Ashmos \& Duchon, 2000) looking at its relevance to educational institutions. The sample items are 'I experience joy in my work' and 'I believe others experience joy as a result of my work'. Subjective well-being scale was designed around the idea that one must ask subjects for an overall judgment of their life in order to measure the concept of life satisfaction. Subjective well-being is measured with a five-item scale developed by Diener, Emmons, Larsen, and Griffin (1985). Sample items included, 'In most ways, my life is close to my ideal'. Job satisfaction has been conceptualized as the extent of the positive affective orientation towards a job. Job satisfaction is measured using the scale developed by Jenkins, Nadler, Lawler, and Cammann (1975). The scale consisted of three items. Sample item included is, 'I get a feeling of personal satisfaction in Doing my job'. The job performance questionnaire was developed and validated in the context of the specific responsibility of employees during their work to evaluate the formal performance requirement for their job. To measure teachers' job performance scale developed by Lynch, Eisenberger, and Armeli (1999) was used. This scale comprised of nine items. Sample items included were, 'Employees perform tasks that are expected of them' and 'Employees exhibit punctuality in arriving at their work station on time after breaks'. Response categories against each item for all the above scales included in the study were on a five-point Likert scale ranging from strongly disagree $=1$ to strongly agree $=5$.

\section{Data Analysis and Results}

Data were screened for potential errors before utilizing them for further analysis. Missing values for all the study variables were far less than five per cent, and hence series mean substitution method was adopted (Hair, Anderson, Tatham \& Black, 1998). Data were also verified for the outliers. Descriptive statistics were performed by using SPSS 20.0 version software, causal inferences and mediation analysis were done using SmartPLS 3.0 Partial least squares structural equation modelling (PLS-SEM) and Microsoft Excel. SmartPLS 3.0 is a variance-based structural equation modelling technique that is used to model latent variables and the relationships between them (Henseler, 2017). Table 1 shows the descriptive information about the data such as mean and standard deviation for all the study variables. It displays correlation analysis to verify the strength, direction and level of significance among the study variables. The table also presents scale reliability with the help of Cronbach's Alpha. Composite reliability, average variance extracted values which are needed to establish convergent, and discriminant validity of all variables are shown.

Table 1. Descriptive Statistics, Reliability coefficients, Correlations among latent variables, AVEs (diagonal values in italics) and Square root of AVEs (values in parenthesis) are shown.

\begin{tabular}{|c|c|c|c|c|c|c|c|c|}
\hline Variable & Mean & $\begin{array}{c}\text { Standard } \\
\text { Deviation } \\
\text { (SD) }\end{array}$ & $\begin{array}{c}\text { Reliability } \\
\text { (Cronbach's } \\
\text { Alpha) }\end{array}$ & $\begin{array}{c}\text { Composite } \\
\text { Reliability }\end{array}$ & SP & JS & JP & SWB \\
\hline SP & 3.93 & 0.82 & 0.88 & 0.91 & $.58(.76)$ & & & \\
\hline JS & 3.99 & 0.97 & 0.88 & 0.93 & $.65^{* *}$ & $.81(.90)$ & & \\
\hline JP & 3.95 & 0.85 & 0.9 & 0.92 & $.72^{* *}$ & $.71 * *$ & $.57(.75)$ & \\
\hline SWB & 3.77 & 0.94 & 0.87 & 0.91 & $.62^{* *}$ & $.68^{* *}$ & $.73^{* *}$ & $.66(.81)$ \\
\hline
\end{tabular}

Note: All correlations are significant at $* * p<.001$; SP - Spirituality; JS Job Satisfaction, JP - Job Performance, SWB - Subjective Well-being.

To ensure the quality of research work, researchers should verify both the reliability and validity. Reliability is the accuracy in measurements when the measurements are repeated. It can be measured using Cronbach's Alpha and Composite reliability. As the values for Cronbach's alpha are well above the recommended threshold of .70, the reliability of the measurements is considered to be accepted (Fornell \& Larcker, 1981). Validity refers to the capability to measure the right concept. Two important forms of validity are convergent and discriminant validity. Convergent validity refers to indicators of a specific construct are converging towards a large portion of the variance that is in common. One way to verify this is to check AVE values greater than .5 (Hair et al., 1998). In this study, the AVE values were ranging from .57 to .81 , and hence convergent validity is achieved. Discriminant validity refers to indicators within a construct are strongly associated with each other, but are distinct from other constructs indicators. To determine if there exists discriminant validity, square roots of AVEs should be higher than the correlations between constructs. In the present study, the square root of AVE values was ranging from .75 to .90 and was significantly higher than the correlations between constructs and hence, discriminant validity is also achieved (see table 1). Apart from the validity and reliability, one another important concept is to check for the multi-colinearity problem. High collinearity between two or more indicators can seriously bias the results. Hence, indicators belonging to each construct were tested for such problems. Collinearity statistics that is variance Inflation factor (VIF) values were within the threshold limit of 3.3, for present study it was ranging from $1.41-2.98$. A rule of thumb in the use of PLS for analysis, as well as the methodological research, suggests that VIFs of 3.3 or less to avoid the issues of multi-collinearity and high interassociations among variables (Kock \& Lynn, 2012). 


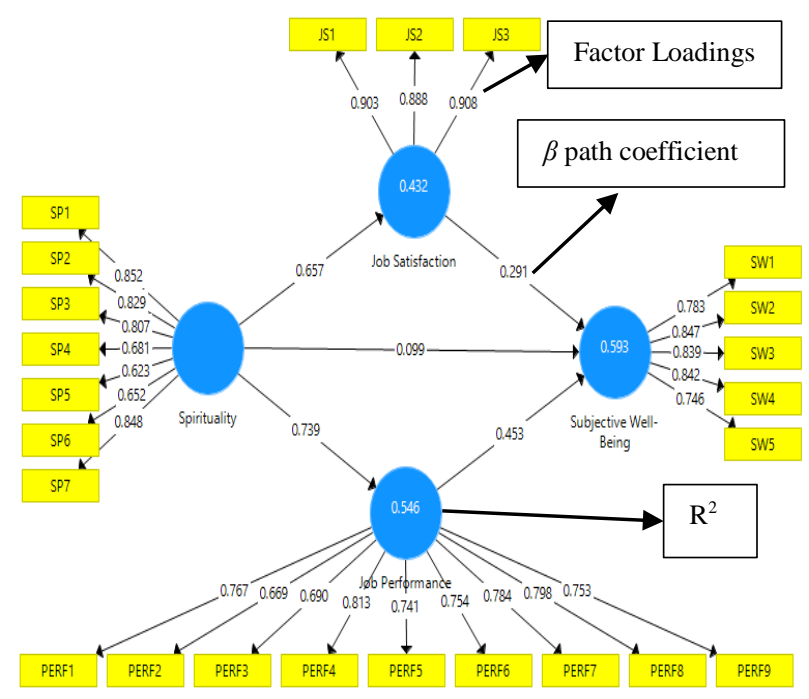

Figure 2: Outer Loadings of Indicators (Factor loadings), Inner values ( $\beta$ path coefficients), and $\mathrm{R}^{2}$ values are shown. All the loading are significant at $\mathrm{P}<.001$, whereas $\beta$ path coefficient between Spirituality and Subjective well-being is significant at $\mathrm{p}<.05$. All the item loadings that were considered for the present study were measured above .50. and were significant.

\section{Model Quality}

Once the reliability and validity of the model are established, researchers proceed to evaluate the hypothesized causal relationships and the quality of the model. Unlike Covariance based Structural Equation Modeling (CB-SEM), PLS-SEM does not have a standard goodness-of-fit statistic (Henseler \& Sarstedt, 2013). Instead, the model's quality can be assessed based on the ability of its exogenous (Independent) constructs to predict the endogenous (dependent) constructs. Coefficient of determination $\left(\mathrm{R}^{2}\right)$ is a measure of the model's predictive accuracy. $\mathrm{R}^{2}$ value ranges from 0 to 1 , where 1 represents complete predictive accuracy. Rule of thumb regarding an acceptable $\mathrm{R}^{2}$ with $0.75,0.50,0.25$, respectively, describing substantial, moderate, or weak levels of predictive accuracy (Hair et al., 2011). For the present model, the $\mathrm{R}^{2}$ value is .593 , which gives an idea that the exogenous constructs of the model have achieved moderate to substantial prediction accuracy. However, $\mathrm{R}^{2}$ will increase even if a non-significant and slightly correlated construct is added to the model. Hence, Hair Jr, Sarstedt, Hopkins, and Kuppelwieser, (2014) suggests considering adjusted $\mathrm{R}^{2}$, which penalizes increasing model complexity by reducing the (adjusted) $\mathrm{R}^{2}$ when additional constructs are added to the model. For the present model, even the adjusted $\mathrm{R}^{2}$ value is healthy at .59 . However, according to Hair, et al., (2018) criteria for evaluating the goodness-of-fit of a PLS-SEM model includes fit indices like Standardized Root Mean Square Residual (SRMR) and Normed Fit Indice (NFI). SRMR for the present model is 0.07 (less than .08 which is an ideal value), and NFI is found to be 0.9 , which is an acceptable value. This suggests that this model has a sound fit indices.

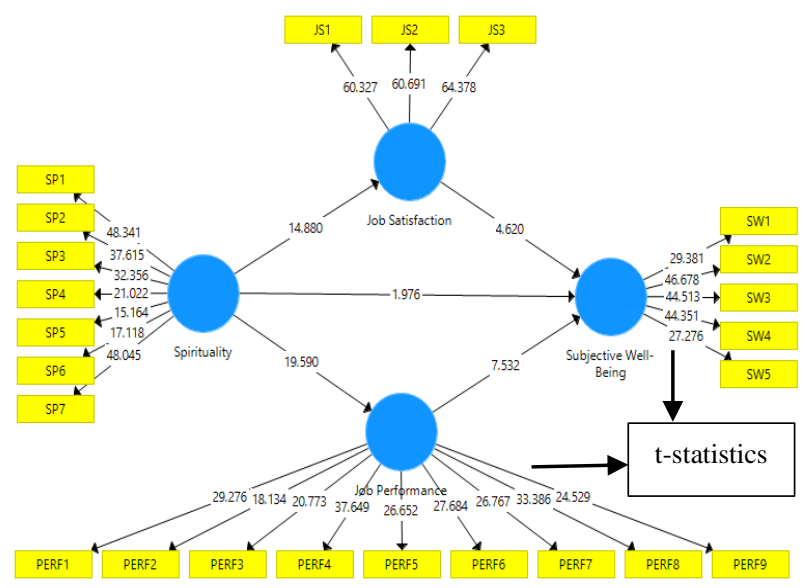

Figure 3: t-statistics is shown for all the indicator variables and for the $\beta$ path coefficients of the model. Note: Significance of each parameter can be determined using t-values.

The primary step in using PLS-SEM is to create a path model based on a strong theoretical foundation (Hair et al., 2014). The proposed model was developed with no circular relationship between the constructs as PLS-SEM can only handle models that have no circular relationship between the constructs. Figure 2 shows the results of $\beta$ coefficients for each link, and they represent the standardized regression path coefficients associated with statistically significant effects.

Table 2. Summary of hypothesized causal relationship results

\begin{tabular}{|c|c|c|c|c|}
\hline $\begin{array}{c}\text { Sl. No. of } \\
\text { Hypothesis }\end{array}$ & $\begin{array}{c}\text { Hypothesized } \\
\text { Relations }\end{array}$ & $\begin{array}{c}\text { Path } \\
\text { Coefficients } \\
(\beta)\end{array}$ & t-statistic & Result \\
\hline $\mathrm{H}_{1}$ & $\mathrm{SP} \rightarrow \mathrm{JS}$ & $.657^{* *}$ & 14.88 & Accepted \\
\hline $\mathrm{H}_{2}$ & $\mathrm{SP} \rightarrow \mathrm{JP}$ & $.739 * *$ & 19.59 & Accepted \\
\hline $\mathrm{H}_{3}$ & $\mathrm{SP} \rightarrow \mathrm{SWB}$ & $.099^{*}$ & 1.976 & Accepted \\
\hline $\mathrm{H}_{4}$ & $\mathrm{JS} \rightarrow \mathrm{SWB}$ & $.291^{* *}$ & 4.62 & Accepted \\
\hline $\mathrm{H}_{5}$ & $\mathrm{JP} \rightarrow \mathrm{SWB}$ & $.453^{* *}$ & 7.53 & Accepted \\
\hline
\end{tabular}

Note: ** significant at $p<.001, *$ significant at $p<.05$ level; SP - Spirituality;

JS - Job Satisfaction, JP - Job Performance, SWB - Subjective well-being

It can be seen from table 2, that workplace spirituality has a significant positive impact on teachers' job satisfaction, teachers' job performance, and teachers' subjective wellbeing with $(\beta=.657, p<.001, \mathrm{t}=14.88), \quad(\beta=.739, p<.001$, $\mathrm{t}=19.59)$, and $(\beta=.099, p<.05, \mathrm{t}=1.976)$ respectively. Hence, hypotheses $H_{1}, H_{2}$, and $H_{3}$ were accepted. Similarly, teachers' job satisfaction and teachers' job performance have a significant positive impact on teachers' subjective well-being with $(\beta=.291, p<.001, \mathrm{t}=4.62)$, and $(\beta=.453, p<.001, \mathrm{t}=7.53)$ respectively, hence $H_{4}$, and $H_{5}$ were also accepted. The strength of each path of the structural model and the variance (R-squared coefficients) of endogenous variables should be greater than .1 (Falk \& Miller, 1992). Figure 2 shows that the $\mathrm{R}^{2}$ coefficient of job satisfaction, job performance, and subjective well-being is $.432, .546$, and .593 respectively. $\mathrm{R}^{2}$ of .593 for endogenous construct teachers' subjective wellbeing essentially means a good amount of variance is 
Journal of Engineering Education Transformations, Volume 33, January 2020, Special issue, eISSN 2394-1707 explained by variables such as workplace spirituality, teachers' job satisfaction, and teachers' job performance put together. The t-statistics of significant paths were above 1.96, as mentioned in table 2 . Any value for t-statistic above 1.96 is considered to be having significant level (Hair, Hult, Ringle \& Sarstedt, 2016). Hence, the structural model is validated.

\section{Mediation Analysis}

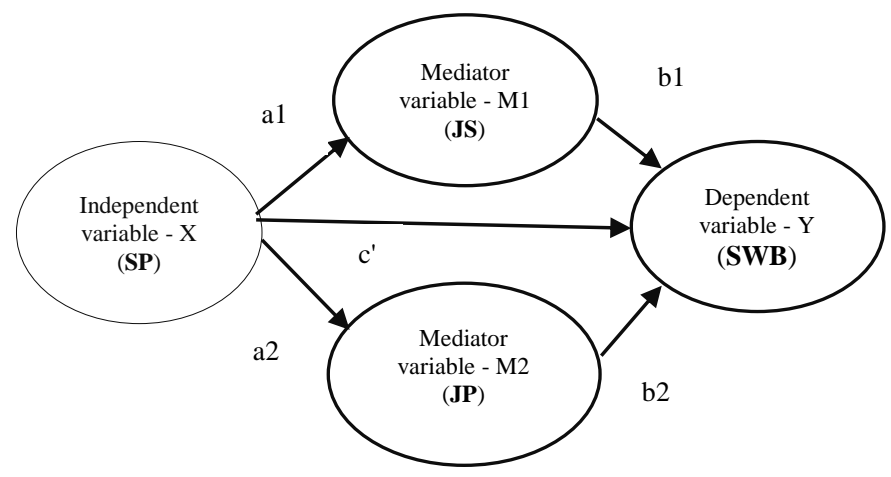

Figure 4: Multiple Mediation Model

Note: SP - Spirituality; JS - Job Satisfaction, JP - Job Performance, SWB - Subjective well-being

Partial Least Squares (PLS) Structural Equation Modeling is frequently used in complex path models. Figure 4 shows a PLS-SEM path model with two mediators, that is teachers' job satisfaction (M1) and teachers' job performance (M2). The total effect is equal to the sum total of direct effect $\left(c^{\prime}\right)$ of Workplace Spirituality (X) on Subjective well-being (Y) and the indirect effects of $(a 1 \times b 1) \mathrm{M} 1$ and $(a 2 \times b 2) \mathrm{M} 2$. See figure 4, the calculation of the total effect is given as $c=$ $c^{\prime}+(a 1 \times b 1)+(a 2 \times b 2)$. Preacher and Hayes (2008) expressed that by including multiple mediators and by comparing their specific mediating effects will lead to the growth of competing theories. On this backdrop, the present study is also interested in comparing the strengths of specific mediating effects to find whether mediator (M1) has a stronger mediator effect than mediator (M2), given both the proposed mediators are significant. Mediation analysis was conducted with the help of the bootstrapping method with 5000 bootstrap re-samples and bias-corrected confidence estimates (MacKinnon, Lockwood \& Williams, 2004; Preacher \& Hayes, 2004). Following the procedure suggested by Nitzl et al. (2016) bootstrapping outputs (i.e., $a 1 \times b 1$ and $a 2 \times b 2$ ) for all 5000 samples were calculated, the percentile and bias-corrected confidence intervals were calculated using a spreadsheet. A significant indirect effect of $\mathrm{a} \times \mathrm{b}$ is required for establishing a mediation effect. A bootstrap test should be used to test the significance of the indirect effect $\mathrm{a} \times \mathrm{b}$. If zero is not included in the confidence interval than a researcher can safely assume that there exists a significant indirect effect $a \times b$. See table 3 for a summary of the mediation results, zero is not included in the confidence interval of both indirect effects, i.e., $(a 1 \times b 1)$ and $(a 2 \times b 2)$ and hence hypotheses $\mathrm{H}_{6}$ and $\mathrm{H}_{7}$ were accepted.

\begin{tabular}{|c|c|c|c|c|c|c|}
\hline \multicolumn{6}{|c|}{ Mediation Analysis } & \\
\hline \multicolumn{6}{|c|}{ Bootstrap 90\% confidence intervals (CI) } & \\
\hline & \multirow{2}{*}{ Path Coefficient } & \multicolumn{2}{|c|}{ Percentile } & \multicolumn{2}{|c|}{ Bias Corrected Percentile } & \\
\hline & & 0.5 & 0.95 & 0.5 & 0.95 & \\
\hline \multicolumn{6}{|l|}{ Direct Effects } & \\
\hline H3: $\quad c^{\prime}$ & $0.090^{*}$ & 0.66 & 0.396 & 0.098 & 0.183 & \\
\hline$a 1$ & $0.657 * *$ & 0.66 & 0.727 & 0.659 & 0.726 & \\
\hline$b 1$ & $0.291 * *$ & 0.289 & 0.396 & 0.29 & 0.398 & \\
\hline$a 2$ & $0.739 * *$ & 0.741 & 0.794 & 0.741 & 0.794 & \\
\hline$b_{2}$ & $0.453 * *$ & 0.289 & 0.396 & 0.288 & 0.395 & \\
\hline Indirect effects & Point Estimate & \multicolumn{2}{|c|}{ Percentile } & \multicolumn{2}{|c|}{ Bias Corrected Percentile } & Result \\
\hline H6: $a 1 \times b l$ & $0.191 * *$ & 0.189 & 0.268 & 0.14 & 0.219 & Accepted \\
\hline$H 7: a 2 \times b 2$ & $0.335 * *$ & 0.213 & 0.295 & 0.334 & 0.416 & Accepted \\
\hline Total Indirect Effect & $0.526 * *$ & 0.403 & 0.563 & 0.524 & 0.684 & \\
\hline
\end{tabular}

$\mathrm{JS} \rightarrow \mathrm{SWB}, \mathrm{a} 2: \mathrm{SP} \rightarrow \mathrm{JP}, \mathrm{b} 2: \mathrm{JP} \rightarrow \mathrm{SWB}, \mathrm{c}^{\prime}: \mathrm{SP} \rightarrow \mathrm{SWB}$

According to MacKinnon, Lockwood, \& Williams (2004) rule for mediation says that the mediator acts as a third variable between the independent variable and dependent variable and facilitates the independent variable to influence the dependent variable. Full mediation is indicated in the case where the direct effect $c$ ' is not significant, whereas the indirect effect $a \times b$ is significant (Carrion, Nitzl \& Roldan, 2014). This means only the indirect effect through the mediator exists. Given that $c^{\prime}$ is not significant, and both the indirect and the total indirect effects are significant, a full mediation can be defended. In the present model, the path coefficient for the direct path $c^{\prime}$ is very low with a value of less than 0.1. However, the c' path has achieved significance at $\mathrm{p}<.05$. A more important observation is that both the indirect path coefficients were significant at $p<.001$. Hence, it is safe to predict that both teachers' job satisfaction and teachers' job performance is facilitating the relationship between workplace spirituality and teachers' subjective well-being. However, having a closer look at path coefficients and significance levels of both the indirect paths, teachers' job performance (M2) emerges out to be a strong mediator than teachers' job satisfaction (M1) between the causal relationship of workplace spirituality and teachers' subjective well-being.

\section{Discussion}

Findings of the present study have empirically augmented the findings on the outcomes of workplace spirituality research done earlier. By instilling congenial work culture of openness, inducing spirit to energize the work, and by providing a work environment that gives personal meaning to work rendered by the teachers has many positive outcomes. A few notable benefits are discharging the prescribed job activities with joy, enhances good feeling about entire job situations and leaves teachers both personally and professionally satisfied. Such a spiritually enhanced work environment will ensure teachers to adequately performs a task that is expected of them. It is also found that the teachers spend little or no time in idle conversations when their respective workplace is enriched with spiritual values. Teachers also restore to healthier work practices such as co-operating the administration in delivering their the best towards the institutions' progress, considering the attendance at work is above all and 
completing the assigned duties effectively. Spirituality at the workplace will help teachers in providing a sense of excellent living conditions. They would be satisfied with their life and live with such conditions changing almost nothing. A teacher who is happy with job situations and who is satisfied with their contribution to the institution is expected to feel a close fit between what they had expected from the life and what they have got, ultimately they feel the life that is close to their best. The results of the present study had statistically proved that teachers' job satisfaction and teachers' job performance is facilitating the relationship between teachers' workplace spirituality and teachers' subjective well-being. On the backdrop of the findings, a message is sent out to administrators who are at the help of responsibility. They need to ensure teachers satisfaction with the overall job situations so that they start believing and feeling that they are spending a pleasant, desirable and rewarding life. The finding establishes workplace spirituality as a condition required for teachers' well-being. The study suggests that the administrators must take the initiative to institutionalize spirituality in organizational vision, mission, policies and framework so that the true potential of workplace spirituality could be accrued in every aspect of work life. The present study is probably one of its kind to explore the relationship between workplace spirituality and subjective well-being not only directly but also indirectly through job satisfaction and job performance.

\section{Limitations and Future Scope}

As with almost all research papers, the present article also has certain limitations. Firstly, the sample selected for the study includes teachers who were working for private engineering institutions located in the states of Telangana and Andhrapradesh only. Hence, the generalization of the findings may be considered with caution. Secondly, the present work was carried out based on cross-sectional data; the results could have been better through longitudinal exploration. Future researchers may further explore or replicate the study in Government funded engineering colleges, as the work conditions, funding priorities are different new finding might see the light.

\section{Acknowledgements}

I sincerely thank Mr Sambaji Rao, Assistant Professor of Human Resource Management \& Communication Studies, School of Commerce, Narsee Monjee Institute of Management Studies for helping me in the data collection process.

\section{References}

Abdullah, A., Bilau, A. A., Enegbuma, W. I., Ajagbe, A. M., \& Ali, K. N. (2011). Evaluation of job satisfaction and performance of employees in small and medium sized construction firms in Nigeria. In 2011 2nd International Conference on Construction and Project Management IPEDR (Vol. 15).

Ashmos, D. P., \& Duchon, D. (2000). Spirituality at work: A conceptualization and measure. Journal of management inquiry, 9(2), 134-145.
Bodia, M.A., \& Ali, H. (2012). Workplace spirituality: A spiritual audit of banking executives in Pakistan. African Journal of Business Management, 6(11), 3888-3897. Carrion, Nitzl \& Roldan, 2014

Cohen, A. (2006). The relationship between multiple commitments and organizational citizenship behavior in Jewish and Arab culture. Journal of Vocational Behaviour, 69, 105-118.

Cooper, C. L., \& Robertson, I. (Eds.). (2001). Well-being in organizations: a reader for students and practitioners. Wiley. Côté, J. (1999). The influence of the family in the development of talent in sport. The sport psychologist, 13(4), 395-417.

Cranny, C.J., Smith, P.C. and Stone, E.F. (1992), Job Satisfaction, Lexington Books, New York, NY.

De Neve, J. E., Diener, E., Tay, L., \& Xuereb, C. (2013). The objective benefits of subjective well-being. World happiness report.

Deci, E. L., \& Ryan, R. M. (2008). Self-determination theory: A macrotheory of human motivation, development, and health. Canadian psychology/Psychologie canadienne, 49(3), 182.

Diener, E. (2012). New findings and future directions for subjective well-being research. American Psychologist, 67(8), 590-597.

Diener, E., Emmons, R. A., Larsen, R. J., \& Griffin, S. (1985). The satisfaction with life scale. Journal of Personality Assessment, 49, 71-75.

Dierendonck, D. V., \& Mohan, K. (2006). Some thoughts on spirituality and eudaimonic well-being. Mental health, religion and culture, $9(03), 227-238$.

Duchon, D. and Plowman, D.A. (2005), "Nurturing spirit at work: impact on work unit performance", Leadership Quarterly, Vol. 16, pp. 807-33.

Eid, M., \& Larsen, R. J. (Eds.). (2008). The science of subjective well-being. Guilford Press.

F. Hair Jr, J., Sarstedt, M., Hopkins, L., \& G. Kuppelwieser, V. (2014). Partial least squares structural equation modeling (PLS-SEM) An emerging tool in business research. European Business Review, 26(2), 106-121.

F. Hair Jr, J., Sarstedt, M., Hopkins, L., \& G. Kuppelwieser, V. (2014). Partial least squares structural equation modeling (PLS-SEM) An emerging tool in business research. European Business Review, 26(2), 106-121.

Falk, R. F., \& Miller, N. B. (1992). A primer for soft modeling. University of Akron Press.

Fornell, C.G. and Larcker, D.F. (1981), "Evaluating structural equation models with unobservable variables and measurement error", Journal of Marketing Research, Vol. 18 No. 1, pp. 39-50.

Fredrickson, B. L., \& Losada, M. F. (2005). Positive affect and the complex dynamics of human flourishing. American psychologist, 60(7), 678.

Fry, L. W. (2003). Toward a theory of spiritual leadership. The Leadership Quarterly, 14(6), 693- 727.

Fry, L. W., Vitucci, S., \& Cedillo, M. (2005). Spiritual leadership and army transformation: Theory, measurement, and establishing a baseline. The leadership quarterly, 16(5), 835-862. 
Journal of Engineering Education Transformations, Volume 33, January 2020, Special issue, eISSN 2394-1707 Fry, L.W. (2005). Toward a paradigm of spiritual leadership. The Leadership Quarterly, 16(5), 619-622.

Fry, L.W., Vitucci, S. and Cedillo, M. (2005), "Spiritual leadership and army transformation: theory, measurement, and establishing a baseline", Leadership Quarterly, Vol. 16, pp. 835-62.

Garg, N. (2017). Workplace spirituality and employee wellbeing: An empirical exploration. Journal of Human Values, 23(2), 129-147.

George, J. M., \& Brief, A. P. (1992). Feeling good-doing good: a conceptual analysis of the mood at workorganizational spontaneity relationship. Psychological bulletin, 112(2), 310 .

Giacalone R, Jurkiewicz C (2003/2010) Handbook of workplace spirituality and organizational performance. ME Sharpe, Armonk

Hair Jr, J. F., Hult, G. T. M., Ringle, C., \& Sarstedt, M. (2016). A primer on partial least squares structural equation modeling (PLS-SEM). Sage publications.

Hair, J. F., Anderson, R. E., Tatham, R. L., \& William, C. (1998). Black (1998). Multivariate data analysis, 5, 87-135.

Hair, J. F., Black, W. C., Babin, B. J., Anderson, R. E., \& Tatham, R. L. (2006). Multivariate data analysis (Vol. 6).

Hair, J. F., Hult, G. T. M., Ringle, C. M., and Sarstedt, M. (2017). A Primer on Partial Least Squares Structural Equation Modeling (PLS-SEM), 2nd edition. Thousand Oaks: Sage.

Hair, J.F., Hult, G.T.M., Ringle, C.M. and Sarstedt, M. (2014), A Primer on Partial Least Squares Structural Equation Modeling, Sage, Thousand Oaks, CA.

Hair, J.F., Ringle, C.M. and Sarstedt, M. (2011), "PLS-SEM: indeed a silver bullet", Journal of Marketing Theory and Practice, Vol. 19 No. 2, pp. 139-151.

Harter, J. K., Schmidt, F. L., \& Hayes, T. L. (2002). Business-unit-level relationship between employee satisfaction, employee engagement, and business outcomes: A meta-analysis. Journal of applied psychology, 87(2), 268. Harung, H. S., Travis, F., Pensgaard, A. M., Boes, R., Cook- Greuter, S., \& Daley, K. (2011). Higher psychophysiological refinement in world- class Norwegian athletes: brain measures of performance capacity. Scandinavian Journal of Medicine \& Science in Sports, 21(1), 32-41.

Henseler, J. (2017). Bridging design and behavioral research with variance-based structural equation modeling. Journal of advertising, 46(1), 178-192.

Henseler, J. and Sarstedt, M. (2013), "Goodness-of-fit indices for partial least squares path modeling", Computational Statistics, Vol. 28 No. 2, pp. 565-580.

Herzberg, F., Maunser, B. and Snyderman, B.(1959), The Motivation to Work, John Wiley and Sons Inc., New York, NY.

Jenkins, G. D., Nadler, D. A., Lawler, E. E., \& Cammann, C. (1975). Standardized observations: An approach to measuring the nature of jobs. Journal of Applied Psychology, 60, 171-181.

Johns, G., \& Saks, A. M. (2001), Organizational behaviour: Understanding and managing life at work. Journal of Management Inquiry, Vol. 9 No. 2, pp. 134-45. Judge, T. A., \& Watanabe, S. (1993). Another look at the job satisfaction-life satisfaction relationship. Journal of applied psychology, 78(6), 939.

Judge, T. A., Klinger, R., Simon, L. S., \& Yang, I. W. F. (2008). The contributions of personality to organizational behavior and psychology: Findings, criticisms, and future research directions. Social and Personality Psychology Compass, 2(5), 1982-2000.

Kanungo, R. N. (1982). Measurement of TUB and work involvement. Journal of Applied Psychology, 67, 341-349.

Karakas, F (2010). Spirituality and Performance in Organisations: A literature review. Journal of Business Ethics, 94(1), 89-106.

Kock, N., \& Lynn, G. (2012). Lateral collinearity and misleading results in variance-based SEM: An illustration and recommendations. Journal of the Association for Information Systems, 13(7).

Krahnke, K., Giacalone, R. A., \& Jurkiewicz, C. L. (2003). Point-counterpoint: Measuring workplace spirituality. Journal of organizational change management, 16(4), 396405.

Krishnakumar, S., \& Neck, C. P. (2002). The "what", "why" and "how" of spirituality in the workplace. Journal of managerial psychology, 17(3), 153-164.

Kumar, S. P., \& Giri, V. N. (2015). Impact of Engineering Faculty Participation in Decision Making and Commitment on Organizational Citizenship Behaviour. Journal of Engineering Education Transformations, 28(4), 56-66.

Locke, E. A. (1976). The nature and causes of job satisfaction. Handbook of industrial and organizational psychology. Chicago: RandMc Narlly.

Lodhal, T. M., \& Kejner, M. M. (1965). The definition and measurement of job involvement. Journal of Applied Psychology, 49, 24-33.

Lynch, P. D., Eisenberger, R., \& Armeli, S. (1999). Perceived organizational support: Inferior versus superior performance by wary employees. Journal of applied psychology, 84(4), 467.

MacKinnon, D. P., Lockwood, C. M., \& Williams, J. (2004). Confidence limits for the indirect effect: Distribution of the product and resampling methods. Multivariate behavioral research, 39(1), 99-128.

Miller, W. R., \& Thoresen, C. E. (2003). Spirituality, religion, and health: An emerging research field. American psychologist, 58(1), 24.

Milliman, J., Czaplewski, A. J., \& Ferguson, J. (2003). Workplace spirituality and employee work attitudes: An exploratory empirical assessment. Journal of organizational change management, 16(4), 426-447.

Mitroff, I.I. \& Denton, E.A. (1999). A study of spirituality in the workplace, Sloan Management Review, 40, 83-92.

Moore TW, Casper WJ (2006) An examination of proxy measures of workplace spirituality: a profile model of multidimensional constructs. J Leadersh Org Stud 12(4):109-118

Morrison, M., Tay, L., \& Diener, E. (2012). Subjective wellbeing across the lifespan worldwide. Paper submitted for publication, University of Western Ontario. 
Neck, C. P., \& Milliman, J. F. (1994). Thought selfleadership: Finding spiritual fulfilment in organizational life. Journal of managerial psychology, 9(6), 9-16.

Nitzl, C., Roldan, J. L., \& Cepeda, G. (2016). Mediation analysis in partial least squares path modeling: Helping researchers discuss more sophisticated models. Industrial management \& data systems, 116(9), 1849-1864.

Page, K. M., \& Vella-Brodrick, D. A. (2009). The 'what', 'why'and 'how' of employee well-being: A new model. Social Indicators Research, 90(3), 441-458.

Pandey, A., Gupta, R. K., \& Arora, A. P. (2009). Spiritual climate of business organizations and its impact on customers' experience. Journal of business ethics, 88(2), 313-332.

Peng, Y. P. (2014), Job satisfaction and job performance of university librarians: A disaggregated examination. Library \& Information Science Research, 36, 74-82.

Peterson, S. J., Luthans, F., Avolio, B. J., Walumbwa, F. O., \& Zhang, Z. (2011). Psychological capital and employee performance: A latent growth modeling approach. Personnel Psychology, 64, 427-450.

Pfeffer, J. (1998). The human equation. Boston: Harvard Business School Press.

Pradhan, R. K., \& Jena, L. K. (2016). Workplace spirituality and employee job Behaviour: An empirical investigation in Indian manufacturing organizations. Paradigm, 20(2), 159175.

Preacher, K. J., \& Hayes, A. F. (2004). SPSS and SAS procedures for estimating indirect effects in simple mediation models. Behavior research methods, instruments, \& computers, 36(4), 717-731.

Preacher, K. J., \& Hayes, A. F. (2008). Asymptotic and resampling strategies for assessing and comparing indirect effects in multiple mediator models. Behavior research methods, 40(3), 879-891.

Rastogi, A., \& Prakash Pati, S. (2015). Towards a conceptualization of Karma Yoga.

Saks, A. M. (2006). Antecedents and consequences of employee engagement. Journal of managerial psychology, 21(7), 600-619.

Sass, J. (2000). Characterizing organizational spirituality: An organizational communication culture approach. Communications Studies, 51(3), 195-217.

Shankar Pawar, B. (2009). Individual spirituality, workplace spirituality and work attitudes: An empirical test of direct and interaction effects. Leadership \& Organization Development Journal, 30(8), 759-777.

Slater, S (1995). Learning to change, Business Horizons, 38, 13-18

Smith, P.C., Kendall, L.M., \& Hulin, C.L. (1969). The measurement of satisfaction in work and retirement. Chicago: Rand-McNally.

Somech, A., \& Drach-Zahavy, A. (2000). Understanding extra-role behaviour in schools: The relationships between job satisfaction, sense of efficacy, and teachers' extra-role behaviour. Teaching and Teacher Education, 16, 649-659.

Umashankar, V., \& Dutta, K. (2007). Balanced scorecards in managing higher education institutions: An Indian perspective. International Journal of Educational Management, 21, 54-67.

Veenhoven, R. (1988). The utility of happiness. Social indicators research, 20(4), 333-354.

Veenhoven, R. (1988). The utility of happiness. Social indicators research, 20(4), 333-354.

Weiss, A., Bates, T. C., \& Luciano, M. (2008). Happiness is a personal (ity) thing: The genetics of personality and wellbeing in a representative sample. Psychological science, 19(3), 205-210.Blau, G. (1985). A multiple study investigation of the dimensionality of job involvement. Journal of Vocational Behavior, 27, 19-36.

Zhai,Q.,Willis,M.,O'Shea,B.,Zhai,Y.,\&Yang,Y. (2013). Big five personality traits, job satisfaction, and subjective wellbeing in China. International Journal of Psychology, 48(6), 1099-1108. 